\title{
nature
}

\section{A timely boost to research on carbon sequestration}

Removing carbon dioxide from the atmosphere is as important as controlling emissions. Basic and applied research need to be pursued in the face of political obstacles.

A longside attempts to limit mankind's production of greenhouse gases, there is a pressing need to find ways of removing carbon from the atmosphere and 'sequestering' it in the land, in geological formations and in the oceans. The US government has now taken laudable steps in that direction, but there is a danger that progress could continue to be unjustifiably hindered.

Nearly two years ago, the US President's Committee of Advisors on Science and Technology issued a report that included a recommendation for the US Department of Energy (DoE) to increase research and development in carbon sequestration. The DoE has now announced the creation of two centres to examine ocean and terrestrial sequestration methods. It is also soliciting proposals for research, to the tune of at least \$18 million, towards the separation and capture of carbon dioxide from the atmosphere, as well as sequestration (see page 315 ).

Hitherto, the political climate in Washington has kept this research pinned to the drawing-board. Some politicians in Congress oppose anything suggesting that the United States might be conforming with the Kyoto Protocol negotiated to address global warming. Politicians also see the projected costs of sequestration, and fear the drag on the US economy. Meanwhile, environmentalists have been slow to embrace sequestration research, believing it might undermine hardwon gains in renewable energy and conservation efforts.

At a DoE workshop on sequestration last week, researchers were bullish about ocean and geological sequestration research. More positively still, there is an encouraging level of cooperation between the agency's Office of Science and Office of Fossil Energy — offices that haven't always had a smooth working relationship. But on sequestration, the Office of Science's orientation towards more basic research appears to fit well alongside the more applied outlook of the Office of
Fossil Energy. Such cooperation will be necessary to lead the way as the complexities and costs of sequestration become better understood. This cooperative attitude must also extend to the partnerships between scientists and industry if large-scale sequestration is to be made reality.

For significant sequestration to be feasible, much more basic research must be conducted, particularly in the oceans. Already, some companies are fertilizing the ocean with nutrients to increase fish harvests while trumpeting the additional benefits of sequestration. Research on ocean 'scrubbing' (enhanced rates of removal by organisms) as well as carbon dioxide 'injection' (disposal in liquid form for hundreds of years at depths below one kilometre or so) needs to come before the application of such commercial efforts, especially given the possible ecological consequences of such practices.

That is why a planned experiment off Hawaii is so important, and requires active support. Scientists at the Pacific International Center for High Technology Research, collaborating with an international team, are planning to inject liquefied carbon dioxide at a depth of about 900 metres off the Kona coast. The experiment, proposed for the Natural Energy Laboratory of Hawaii, would be conducted in 2001 in an established research corridor in the ocean. It is designed to gather the environmental data to properly assess future sequestration experiments. The authority that governs the Natural Energy Laboratory has yet to approve the experiment. But some environmental groups fear that it will harm the ocean ecosystem and give encouragement to the construction of another power plant. Scientists fear that the entire experiment may be jeopardized by delays. If the opportunity to conduct a reasoned environmental-assessment experiment disappears, both environment and science will be the losers.

\section{Reclusion to be discouraged}

A survey has revealed that many Japanese researchers are disconnected from the outside world. Their institutions can help.

n 1998, Nature published a total of 84 papers from Japan - the highest number ever. That record is likely to be exceeded this year. This continually upward trend would seem to indicate that Japanese researchers are taking a more active role in the international science arena. However, a report released last week by the Science and Technology Agency states otherwise (see page 314).

The report, based on a survey across a wide range of research institutions in Japan, reveals that a significant proportion of Japanese researchers do not publish internationally. According to the report, 40 per cent of researchers submit papers only to Japanese journals. The reason behind this, say researchers who responded to the survey, is the fact that many institutions still place a strong emphasis on the numerical output of research papers as a criterion for evaluating research performance. Such a system forces many Japanese researchers, including highly talented ones, to shy away from international journals with high impact factors and to turn instead to
Japanese publications, which provide a better opportunity for their papers to get published.

But the system alone cannot be blamed for Japanese scientists' lack of involvement in international science. They themselves need to make an effort to enhance their communication with researchers in other countries. The survey reveals that only 20 per cent of researchers communicate regularly with overseas colleagues. A large percentage of them do not communicate at all, and less than half use e-mail and faxes for their communication.

In the age of the Internet, there is every reason to encourage more proactivity on the part of both Japanese and Western scientists in establishing contacts, despite the obstacles posed by language. And for Japanese scientists to rise more frequently to the challenges of international scientific communication, their institutions need to focus more on quality rather than quantity in their assessment of scientific output. 